\title{
Novel Starch-Based Scaffolds for Bone Tissue Engineering: Cytotoxicity, Cell Culture, and Protein Expression
}

\author{
A.J. SAlgAdO, B.Sc., ${ }^{1,2}$ O.P. COUTINHO, Ph.D., ${ }^{2,3}$ and R.L. REIS, Ph.D. ${ }^{1,2}$
}

\begin{abstract}
Starch-based biomaterials and scaffolds have been proposed for several biomedical applications. In the present work new scaffolds based on a 50/50 (wt\%) blend of corn starch/ethylene-vinyl alcohol (SEVA-C) were studied. These scaffolds were processed by a melt-based technology, which has been used before with other starch-based materials but never with SEVA-C. Scanning electron microscopy (SEM) observation showed that the developed porous structures were $60 \%$ porous with pore size between 200 and $900 \mu \mathrm{m}$ and a reasonable degree of interconnectivity. Moreover, scaffolds presented a compressive modulus of $117.50 \pm 3.7 \mathrm{MPa}$ and a compressive strength of $20.8 \pm 2.4 \mathrm{MPa}$. Cytotoxicity evaluation was performed according to ISO/EN 10993 part 5 guidelines, and revealed that the developed scaffolds were nontoxic and did not inhibit cell growth. Direct contact assays were also carried out by use of a cell line of human osteoblast-like cells (SaOS-2). Cells were seeded $\left(3 \times 10^{5}\right.$ per scaffold) and allowed to grow for 4 weeks at $37^{\circ} \mathrm{C}$, in a humidified atmosphere containing $5 \% \mathrm{CO}_{2}$. Total protein assay showed that the cells were able to grow for the 4 weeks of the experiment. These data were further confirmed by SEM. Moreover, a cell viability assay (MTS test) demonstrated that cells were perfectly viable after the 4 weeks of culture, showing the adequacy of the developed structure in supporting them. Finally, Western blot analysis revealed that osteopontin was being actively expressed by the cells, which, in association with collagen deposition observed by SEM, seems to indicate that bone extracellular matrix was being deposited. Consequently it is believed that starch-based scaffolds should be considered as an alternative for bone tissueengineering applications in the near future.
\end{abstract}

\section{INTRODUCTION}

$\mathbf{E}$ VERY YEAR millions of people worldwide suffer from unrecoverable bone lesions such as severe bone fractures or bone ablations due to tumor extraction or to traumatic injuries. ${ }^{1,2}$ The repair of these lesions is a great challenge to reconstructive surgery that has not yet been properly addressed. In fact, current treatments are commonly based on the use of autologous bone for the reconstruction of such lesions. ${ }^{3}$ However, this technique has several limitations such as the limited supply of suitable bone, the pain inflicted on the patient to obtain the explant, the risk of infection, hemorrhage, cosmetic disability, nerve damage, and loss of function among others. ${ }^{3-5}$ However, and despite the fact that materials science technology has resulted in clear improvements in the field of bone substitution medicine, no adequate bone substitute has been developed to date.

In the last decade of the 20th century special emphasis was put on an emerging field of science called tissue

\footnotetext{
${ }^{1}$ Department of Polymer Engineering, University of Minho, Campus de Azurém, Guimarães, Portugal.

23B's Research Group—Biomaterials, Biodegradables, and Biomimetics, University of Minho, Campus de Gualtar, Braga, Portugal.

${ }^{3}$ Department of Biology, University of Minho, Campus de Gualtar, Braga, Portugal.
} 
engineering, which combines state of the art materials science with concepts from life sciences. ${ }^{6}$ Its main purposes are the production of tissues and organ substitutes/equivalents that can replace or restore the natural features and physiological functions of natural tissues in vivo. ${ }^{6,7}$ In this field it is believed that most of the primary cells isolated from organs or tissues are anchorage dependent. Therefore, the presence of a supporting material (scaffolds) that can act as a template for cell growth is essential. ${ }^{7}$ These scaffolds should not only possess an adequate surface chemistry, allowing cell attachment and proliferation, but should also be biocompatible, biodegradable, and porous, in order to allow vascularization and mass transfer to occur where needed. Finally, the scaffolds should exhibit adequate mechanical properties so that the integrity of the neotissue/neorgan can be assured..$^{7-10}$ In the case of bone tissue engineering the latter are of the utmost importance because (1) due to bone characteristics, high rates of mass transfer are expected to occur, even under in vitro culture conditions, and (2) when implanted in vivo, high rates of vascularization should occur. ${ }^{11}$ Moreover, bone is always under continuous stress and hence the mechanical properties of the implanted construct should ideally match those of living bone and must maintain it mechanical stability until the neotissue can assure its mechanical role by itself. At this stage, the scaffold is no longer needed and should be, or in the process of being, completely degraded.

Up to now several materials, from ceramics to natural polymers, as well as processing techniques have been used to develop scaffolds for bone tissue engineering. ${ }^{7,12}$ For instance, bone regeneration has been partially achieved by using coral, ${ }^{3,13}$ hydroxyapatite (HA) or tricalcium phosphate (TCP) based scaffolds. ${ }^{14-16}$ In other cases aliphatic polyesters, such as polyglycolic acid (PGA), polylactic acid (PLA), and poly( $\epsilon$-caprolactone), or their copolymers have been used. ${ }^{12,17-19}$ However, and in spite of the fact that relatively good results were obtained with these materials, they display some problems such as a lack of mechanical stability and brittle nature, in the case of ceramics, ${ }^{7}$ or the release of acidic degradation products that can adversely affect biocompatibility in the case of aliphatic polyesters. ${ }^{7,20}$

As a result, new materials that can be an alternative to those currently used in tissue engineering have been developed. For instance, starch-based thermoplastics have been put forward as candidates for potential biomedical applications, namely as partially degradable bone cements ${ }^{20}$ to be used, drug delivery carriers and hydrogels, ${ }^{21,22}$ and in the bone fixation/filling of bone defects in the orthopedic field. ${ }^{23}$ Their use as scaffolds for tissue engineering was also considered, and recent studies revealed that they had adequate mechanical and degradation properties. ${ }^{9,24}$ As previously described their degra- dation is characterized by a weight loss of about $15-20 \%$ in the first 15 days, after which the materials slowly degrade by chemical attack. ${ }^{9,20}$ Further information on materials degradation mechanisms can be found elsewhere. ${ }^{9}$ It was also found that they are able to support cellular growth. ${ }^{8}$ Furthermore, previous in vivo studies have also shown that these materials not only do not cause any major inflammatory response, but also exhibit bone-bonding behavior when reinforced with bioactive ceramics. ${ }^{25}$

The present study reports on the morphology, mechanical properties, cytocompatibility, cell proliferation, and protein expression of human osteoblast-like cells on novel scaffolds based on a blend of starch with ethylene-vinyl alcohol(SEVA-C), processed by a previously described technique. ${ }^{9}$ This processing is based on extrusion of the raw polymeric material with a certain percentage of nontoxic blowing agents. Results have shown that the developed scaffolds have adequate mechanical properties. Furthermore, they also support the growth of human osteoblastlike cells on their surface and inner regions, with what seemed to be consequent extracellular matrix deposition.

\section{MATERIALS AND METHODS}

\section{Scaffold production}

The polymer used in the present study was a 50:50 (wt\%) blend of corn starch/ethylene-vinyl alcohol (SEVA-C; Novamont, Novara, Italy). Scaffolds were obtained by using a methodology based on extrusion with blowing agents, as previously described by Gomes et al. ${ }^{9}$ Briefly, the polymer was previously mixed with $1 \%$ (wt $\%$ ) of a solid blowing agent based on citric acid (trade name BIH40; Clariant, Muttenz, Switzerland) in a biaxial rotating drum. This mixture was then extruded in a Carvex twin-screw extruder with a $12-\mathrm{mm}$ die, after which the resulting materials were cut into $5 \times 5 \times 5 \mathrm{~mm}^{3}$ samples.

\section{Scaffold characterization}

Pore morphology, namely size, distribution, and interconnectivity, was characterized by scanning electron microscopy (SEM), with a Leica Cambridge S360 (Leica Cambridge, Cambridge, UK). All samples were previously sputter coated with gold (JFC-1100; JEOL, Tokyo, Japan). Pore size measurements were obtained from five micrographs, obtained from six different samples (five micrographs per sample) acquired in the SEM. Pore size was then determined by making the average of several diagonal measurements from the pores, using image analysis software.

Porosity was calculated as follows: (1) weight and volume of each sample ( $n=6)$ were determined; (2) from these measurements, the apparent density of the scaffolds was calculated; and (3) the scaffold porosity was obtained 
on the basis of the following formula: porosity $(\%)=\epsilon=$ $1-\rho^{*} / \rho \times 100\left(\rho_{\text {SEVA-C }}=1.28, \rho^{*}-\right.$ apparent density $)$.

Mechanical properties of the developed scaffolds were assessed in compressive experiments with an Instron 4505 universal testing machine (Instron, Canton, MA) using a load cell of $50 \mathrm{kN}$. Samples $(n=6)$ were previously cut in cylinders with a diameter of $1.5 \mathrm{~cm}$ and a height of $1 \mathrm{~cm}$. The compression tests were carried out at a cross-head speed of $2 \mathrm{~mm} / \mathrm{min}\left(4.7 \times 10^{-5} \mathrm{~m} / \mathrm{s}\right)$ until fracture, or until obtaining a maximum reduction in sample height of $60 \%$.

\section{In vitro cytotoxicity assessment}

In all cytoxicity tests performed, latex rubber (VelosPerforex, Manchester, UK) and standard culture medium were used as positive and negative controls, respectively. Latex rubber is known to have a strong cytotoxic effect leading to extensive cell death and lysis, and is commonly used as a positive control for cell death. To assess the short-term cytotoxicity of the developed scaffolds, the following ISO/EN 10993 part 5 guidelines were used ${ }^{26}$ : MEM extraction and MTS, both with a $24 \mathrm{~h}$ extraction period. These assays are particularly aimed at establishing the possible toxic effects of leachables released from medical polymers during extraction. The objectives of the MEM extraction test are to evaluate changes in cell morphology and growth inhibition, whereas the MTS test determines whether cells are metabolically active.

Cell culture. The present experiment used a cell line of rat lung fibroblasts-L929, obtained from the European Collection of Cell Cultures (ECACC). Cells were grown as monolayers in Dulbecco's modified Eagle's medium (DMEM; Sigma, St. Louis, MO) supplemented with $10 \%$ fetal bovine serum (FBS; Biochrom, Berlin, Germany) and $1 \%$ of an antibiotic-antimycotic mixture (1\%; Sigma), and trypsinized before the experiments. For the MEM extraction tests, cells were seeded in 24 well plates, at a density of $1.25 \times 10^{5}$ cells per well $(n=3)$. For the MTS test, cells were seeded in 96 well plates $(n=6)$, at a density of $2 \times 10^{4}$ cells per well. In both cases cells were incubated for $24 \mathrm{~h}$ at $37^{\circ} \mathrm{C}$, in a humidified atmosphere containing $5 \% \mathrm{CO}_{2}$.

MEM extraction test. In all tests the ratio of material weight to extract fluid was constant and equal to $0.2 \mathrm{~g} / \mathrm{mL}$ for porous samples, whereas for the positive control the ratio of material outer surface to extraction fluid was 2.5 $\mathrm{cm}^{2} / \mathrm{mL}$. Test material $(n=6)$ and positive control were extracted for $24 \mathrm{~h}$ at $37^{\circ} \mathrm{C}$, using complete culture medium as the extraction fluid. Before the tests, culture medium was removed from the wells and an identical volume, $2 \mathrm{~mL}$, of extraction fluid was added. Cell response was evaluated after 24,48 , and $72 \mathrm{~h}$ of incuba- tion time. Parameters analyzed included confluence of the monolayer, degree of floating cells, and changes in morphology. After $72 \mathrm{~h}$ the percentage of growth inhibition was determined by cell counting with a hemocytometer and trypan blue exclusion method. Final measurements were then corrected for the negative control.

MTS test. CellTiter 96 One solution Cell Proliferation Assay kit (Promega, Madison, WI) is based on bioreduction of the substrate, 3-(4,5-dimethylthiazol-2-yl)-5(3-carboxymethoxyphenyl)-2(4-sulfofenyl)- $2 H$-tetrazolium (MTS), into a brown formazan product by dehydrogenase enzymes in metabolically active cells ${ }^{27,28}$ and is commonly used for cell viability evaluation. ${ }^{8}$ The extraction procedure was the one described above for the MEM test, using $200 \mu \mathrm{L}$ of extraction fluid per well. After $72 \mathrm{~h}$ the extraction fluid was removed and $200 \mu \mathrm{L}$ of a mixture, containing serum-free cell culture medium without phenol red, and MTS, was added to each well. Cells were then incubated for $3 \mathrm{~h}$ at $37^{\circ} \mathrm{C}$ in a humidified atmosphere containing $5 \% \mathrm{CO}_{2}$. At this time optical density (OD) was measured with a plate reader (Molecular Devices, Sunnyvale, CA) at $490 \mathrm{~nm}$. The mean OD value obtained for the negative control was standardized as $0 \%$ metabolic inhibition.

\section{Direct contact assays}

Cell seeding on starch-based scaffolds. Human osteosarcoma cells (SaOS-2 cell line; ECACC) were grown as monolayer cultures in DMEM supplemented with $10 \%$ FBS, $1 \%$ antibiotic-antimycotic mixture, $5 \mathrm{mM} \beta$ glycerophosphate (Sigma), and $50 \mu \mathrm{M}$ ascorbic acid (Sigma) until they reached the P10 (passage 10) stage. At that time cells were trypsinized, centrifuged, and resuspended in cell culture medium. Aliquots $(20 \mu \mathrm{L})$ containing $3 \times 10^{5}$ cells were then seeded on top of the porous structures, which had been previously placed in 24 well culture trays. Two hours after cell seeding, $1 \mathrm{~mL}$ of culture medium was added to each well and cell-scaffold constructs were incubated for 4 weeks in a humidified atmosphere at $37^{\circ} \mathrm{C}$, containing $5 \% \quad \mathrm{CO}_{2}$, with medium changes every 3 to 4 days. On the last week of the experiment, and in order to stimulate the mineralization of the extracellular matrix (ECM), dexamethasone (Sigma) was added to the culture medium in a final concentration of $10^{-8} \mathrm{M}$.

Cell proliferation. Cell proliferation of human osteoblast-like cells on starch-based scaffolds was assessed by the Sedmak total protein assay. Twelve hours and 7, 14, 21 , and 28 days after seeding, cell-scaffold constructs $(n=6)$ were washed in $0.15 \mathrm{M}$ phosphate-buffered saline (PBS), lysed in $750 \mu \mathrm{L}$ of lysis buffer (20 mM Tris, 1 mM EDTA, $150 \mathrm{mM} \mathrm{NaCl}$, and 1\% Triton X-100) sup- 
plemented with $100 \mu \mathrm{M}$ phenylmethylsulfonyl fluoride (PMSF; Sigma) and a cocktail of protease inhibitors (chymostatin, leupeptin, antipain, and pepstatin) at a final concentration of $1 \mu \mathrm{g} / \mathrm{mL}$, and finally sonicated three times at $40 \mathrm{kV}(15 \mathrm{~s}$ each). After sonication scaffolds were removed and the resulting suspension was centrifuged for $10 \mathrm{~min}$ at $14,000 \mathrm{rpm}$ and $4^{\circ} \mathrm{C}$ at the end of which the pellet was discarded. Scaffolds without cells but kept under the same culture conditions were used as blanks. For protein quantification $20 \mu \mathrm{L}$ of the protein extract was removed and added to $2 \mathrm{~mL}$ of Sedmak reagent $(0.06 \%$ Coomassie blue in $0.3 \mathrm{M} \mathrm{HClO}_{4}$ ) previously diluted in $0.1 \mathrm{~N} \mathrm{HClO}_{4}$ in a 1.5:3.5 ratio. The reaction was allowed to occur for $10 \mathrm{~min}$, at the end of which absorbance was measured at $620 \mathrm{~nm}$. The results were then plotted against a standard curve made with bovine serum albumin (BSA) ranging from 0 to $25 \mu \mathrm{g}$. Total protein was then calculated by extrapolation for the $750 \mu \mathrm{L}$ of protein extract solution.

Cell viability assay. Cell viability was assessed after $12 \mathrm{~h}$ and $7,14,21$, and 28 days by using the MTS test as described previously. ${ }^{8}$ Briefly, cell-scaffold constructs $(n=6)$ were washed in $0.15 \mathrm{M}$ PBS and placed in a mixture containing serum-free cell culture medium and MTS at a 5:1 ratio and incubated for $3 \mathrm{~h}$ at $37^{\circ} \mathrm{C}$ in a humidified atmosphere containing $5 \% \mathrm{CO}_{2}$, at the end of which $100 \mu \mathrm{L}(n=6)$ was transferred to 96 well plates and the OD determined at $490 \mathrm{~nm}$.

Cell adhesion to SEVA-C scaffolds. The adhesion of human osteoblast-like cells to SEVA-C scaffolds was assessed weekly by SEM. To determine whether cells were growing in a three-dimensional manner into the inner regions of the scaffolds, the latter were cut into portions of

a)

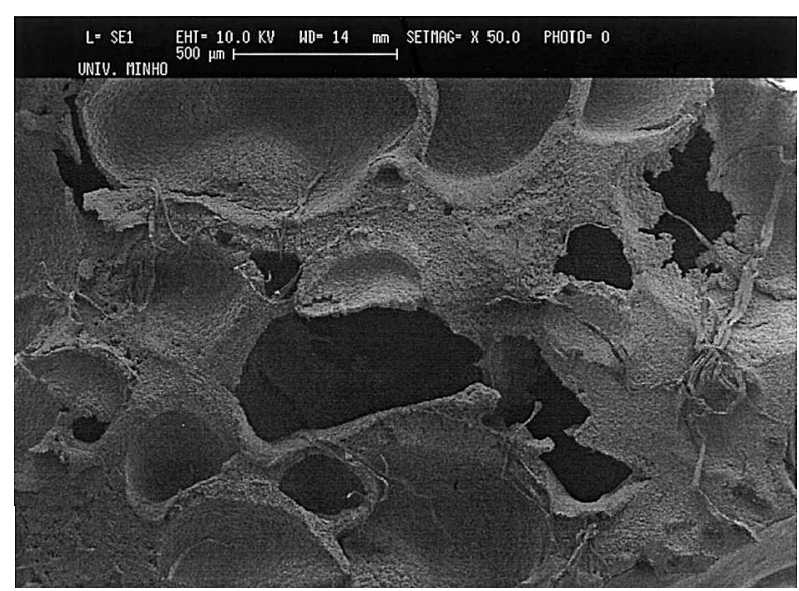

equal size and then observed under the SEM. For that, cell-scaffold constructs were washed in $0.15 \mathrm{M}$ PBS and fixed in $2.5 \%$ glutaraldehyde in PBS. Afterward, the constructs were washed again in PBS, subjected twice to a $50,70,90$, and $100 \%$ ethanol series (15 min each), and finally air dried. Samples were then sputter coated with gold (JEOL JFC-1100) and analyzed with a Leica Cambridge $\mathrm{S} 360$ scanning electron microscope.

Western immunoblot analysis. For Western blot analysis, protein was extracted weekly and quantified as described above (see Cell Proliferation). Aliquots containing equal amounts of protein $(20 \mu \mathrm{g})$ were then loaded into a $4 \%$ stacking polyacrylamide gel and a $10 \%$ running gel, subjected to electrophoresis, and electrotransferred to a Hybond P membrane (Amersham Biosciences, Piscataway, NJ). Membranes were saturated with 5\% (w/v) fat-free dry milk in TBS-T (50 mM Tris, $150 \mathrm{mM}$ $\mathrm{NaCl}, 0.1 \%$ Tween 20, pH 7.6) for $1 \mathrm{~h}$ and $45 \mathrm{~min}$ at room temperature. Blots were then further incubated for $1 \mathrm{~h}$, at room temperature, with primary antibody against osteopontin (University of Iowa, Iowa City, IA) at a 1:200 dilution. After washing with $1 \%$ milk-TBS-T solution, blots were further incubated for $1 \mathrm{~h}$ with anti-mouse IgG antibody coupled to horseradish peroxidase (Amersham Biosciences). The immune complex was detected by incubation with the ECL system (Amersham Biosciences) and visualized by chemiluminescence.

\section{Statistics}

Statistical evaluation was performed using two-tailed paired Student $t$ tests, to assess the statistical differences between groups at different time points. Statistical significance was defined as $p<0.05$ for a $95 \%$ confidence interval.

b)

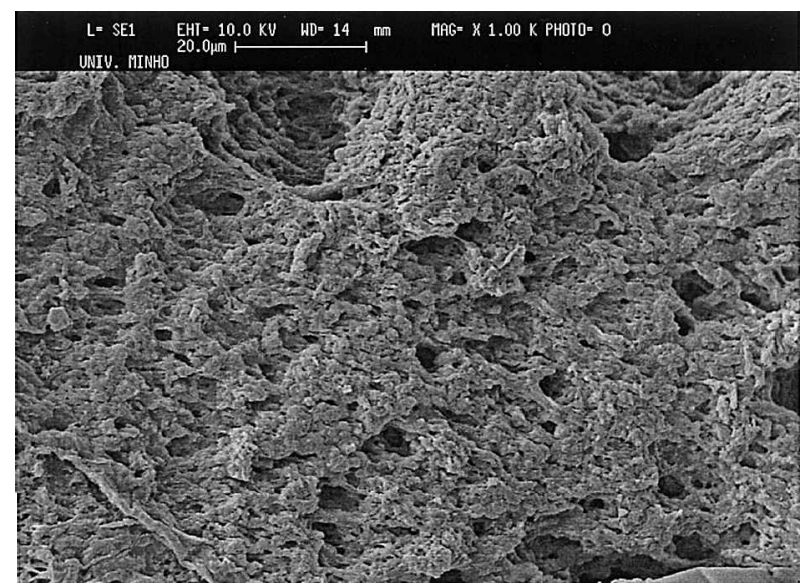

FIG. 1. (a) SEVA-C scaffold obtained by extrusion with blowing agents, presenting $60 \%$ porosity and a pore size of 200 to $900 \mu \mathrm{m}$; (b) microporosity with pore size ranging from 2 to $20 \mu \mathrm{m}$. 
a)

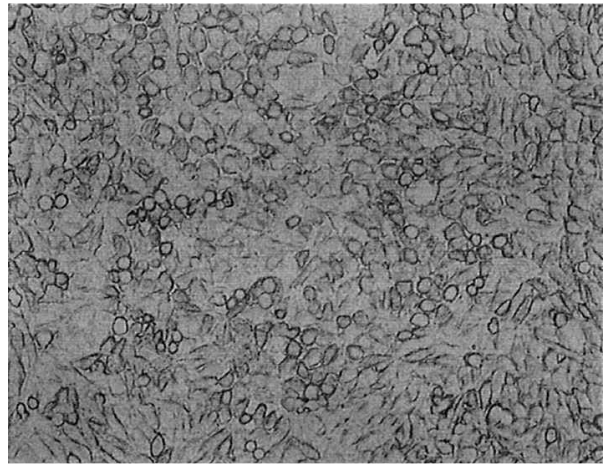

b)

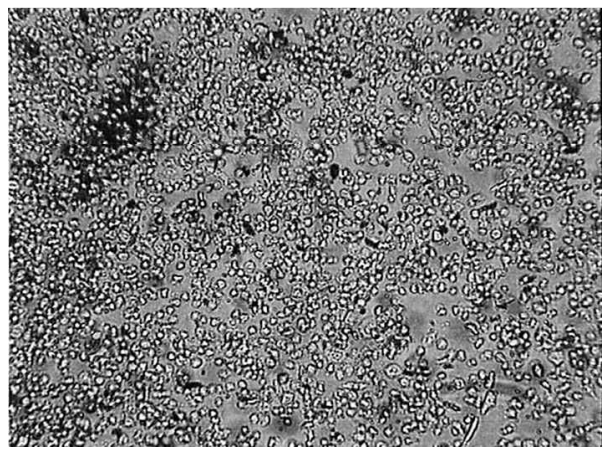

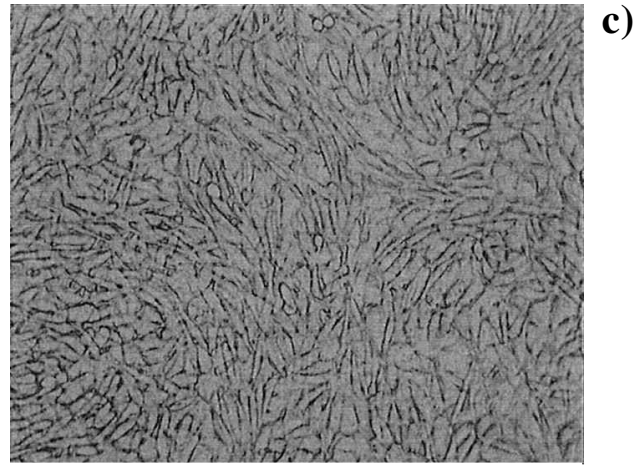

FIG. 2. L929 cells incubated with (a) negative control, (b) positive control, and (c) SEVA-C scaffolds, extracts over a 72-h period (original magnification, $\times 100$ ).

\section{In vitro cytotoxicity assessment}

Regarding the short-term MEM extraction tests, there was no growth inhibition detected after $72 \mathrm{~h}(0.0 \pm 0.0 \%)$ when using the trypan blue exclusion method. In all tests, the negative control did not affect cell proliferation and morphology: a monolayer of normally spread cells could be observed (Fig. 2a). However, the toxic effect of the positive control was clear: cells exhibited severe morphological changes and they were not able to proliferate (Fig. 2b). The tested material, porous SEVA-C scaffolds, did not demonstrate any cytotoxic effect. The extract did not have any effect on L929 cell morphology and proliferation. Under these conditions the cells displayed mor-

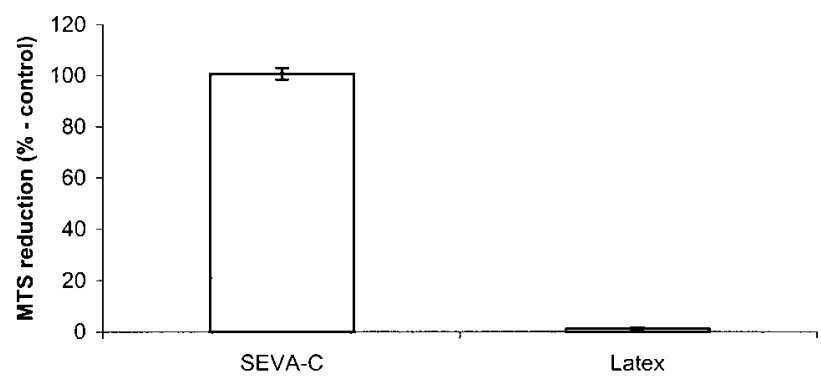

FIG. 3. MTS reduction by L929 cells after incubation with the test and positive control extracts over a period of $72 \mathrm{~h}$. Results are based on optical density measurements and were normalized for the negative control. make them suitable for use in bone tissue engineering. 
a)

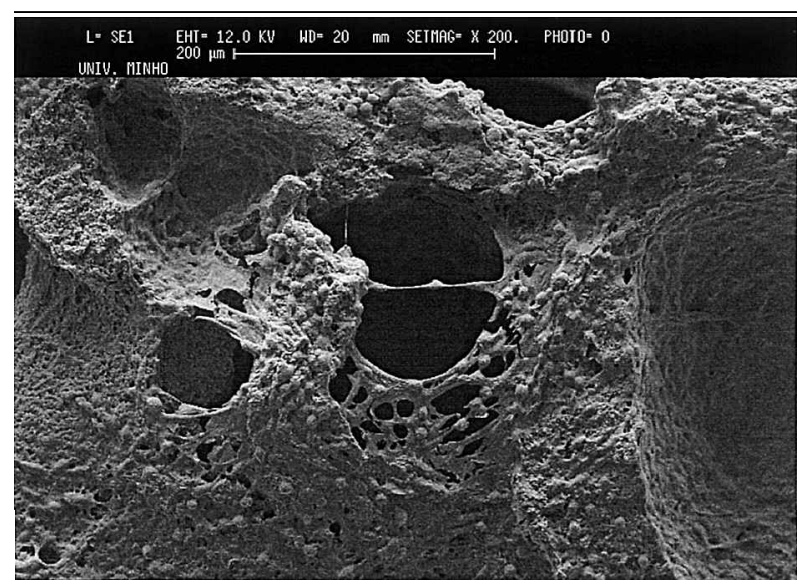

b)

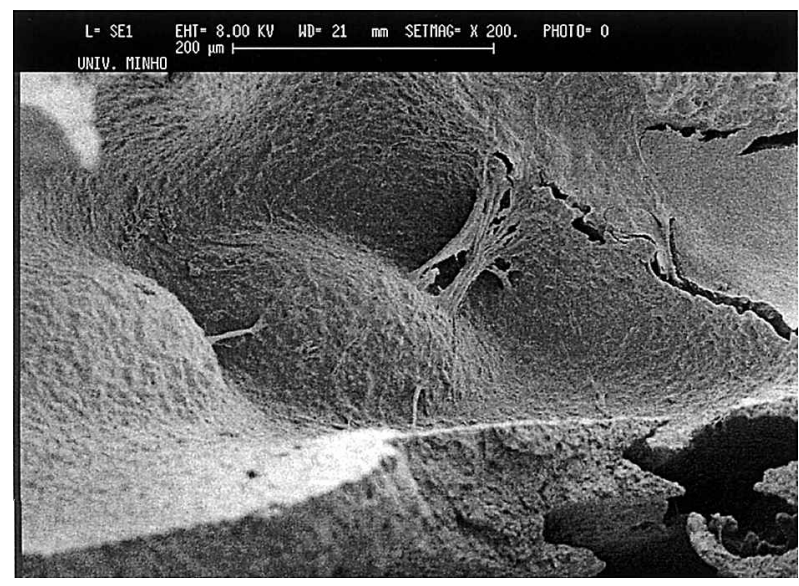

c)

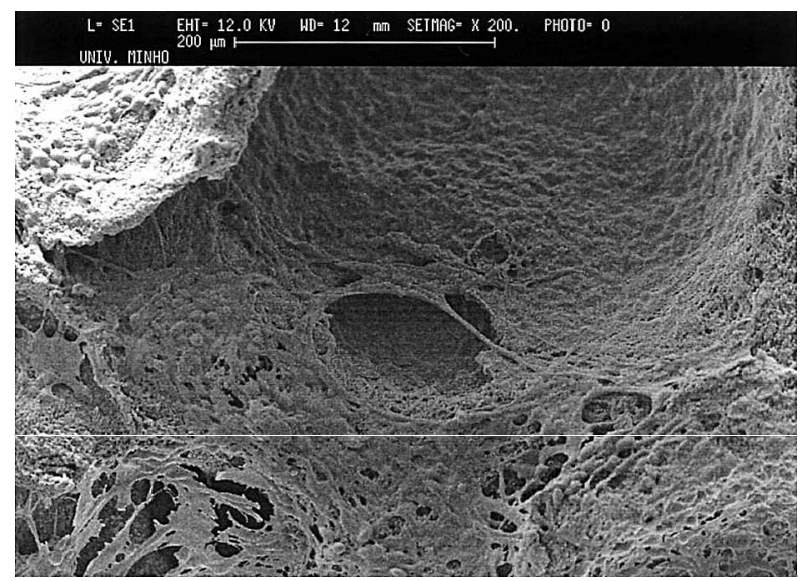

d)

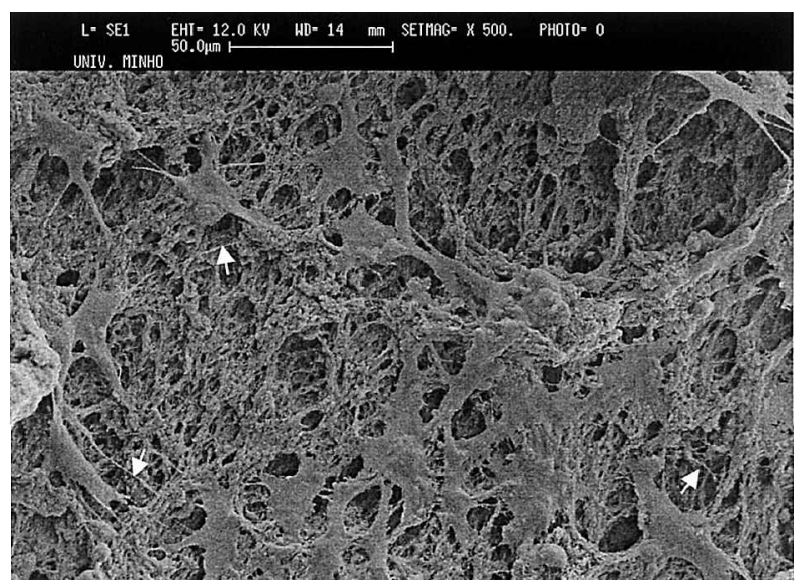

FIG. 4. Scanning electron microscopy (SEM) of SaOS-2 cell adhesion and proliferation on SEVA-C-based scaffolds after (a and b) 1 week, (c and d) 2 weeks, (e and f) 3 weeks, and (g and h) 4 weeks. (b, d, f, and h) Inner regions of the scaffolds, as explained in Materials and Methods. As shown, growth was sequential and, after 1 week in which the cells filled most of the bars of the scaffolds (a) and already some infiltration into the inner parts had occurred (b), cells started to colonize the inner regions of the scaffolds, presenting massive colonization after 4 weeks in culture ( $\mathbf{g}$ and $\mathbf{h})$. Moreover, collagen fibril deposition was observed, indicating the possible deposition of bone extracellular matrix (ECM; arrows) (d).

phologies and proliferation patterns similar to those of the negative control samples (Fig. 2c).

In the MTS test, L929 cells produced large amounts of a brown formazan product after incubation with the tested extract. This is an indicator of normal metabolism (Fig. 3). This fact shows that cells were able to incorporate and metabolize MTS and hence their perfect viability. Furthermore, MTS incorporation under these conditions was similar to that of the negative control, which supports our claims of lack of cytotoxic effects of the tested scaffold material.

\section{Direct contact assays}

The mechanism that dominates initial cell attachment to the surface of a biomaterial, in vitro, is the adsorption on its surface, of proteins from cell culture medium serum. ${ }^{31}$ This film of proteins acts in vitro like the matrix synthesized in vivo by bone-forming cells and its nature, extent, and stability are to a large extent determined by the surface properties of the material and are thus a reflection of the characteristics of the substrate. ${ }^{31,32}$

Regarding the present experiment, SEM observation allowed to determine that osteoblast-like cells were well adhered to SEVA-C based scaffolds after 1 week in culture (Fig. 4a). Cells adhered mainly to the bars of the scaffolds, while at the same time being able to span across pores. This observation demonstrated the adequacy of the pore size range within the SEVA-C scaffold (Fig. 4a). Furthermore, an observation made of the scaffold inner regions (Fig. 4b), as referred to in Materials and Methods, revealed that cells were also capable of colonizing 
e)

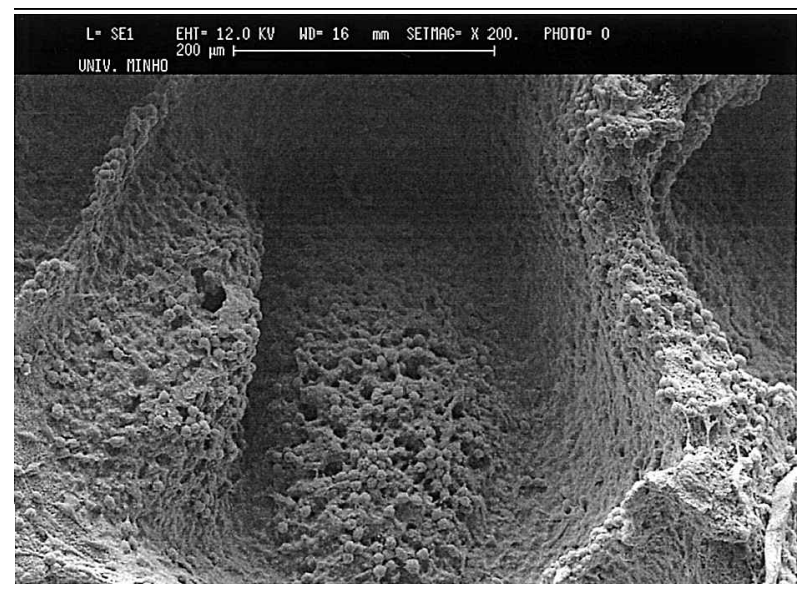

f)

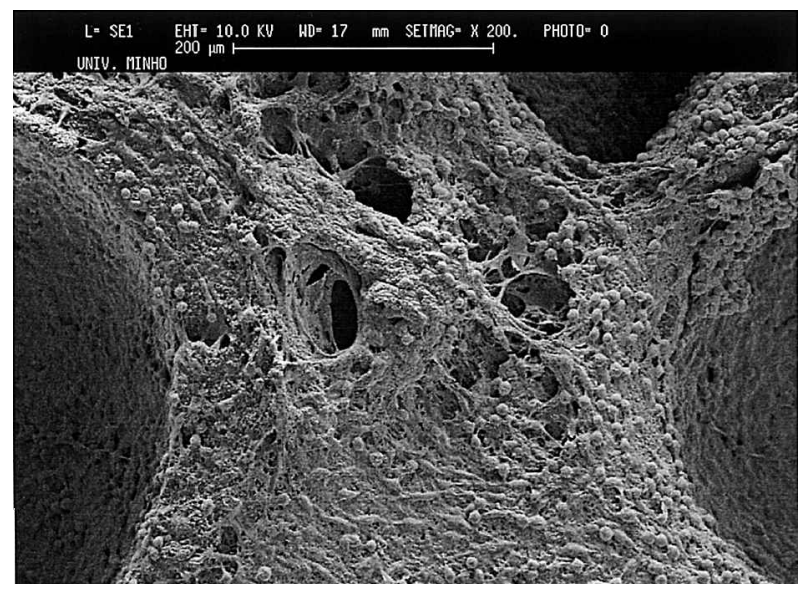

g)

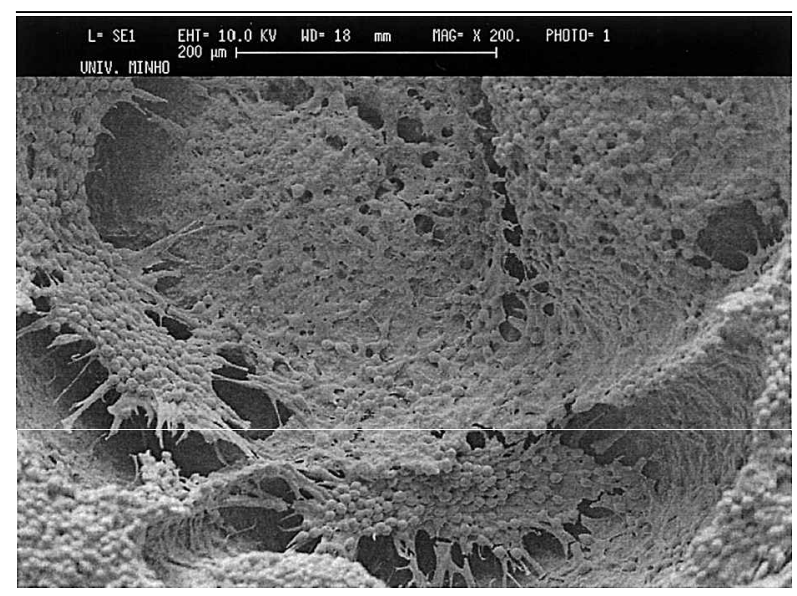

h)

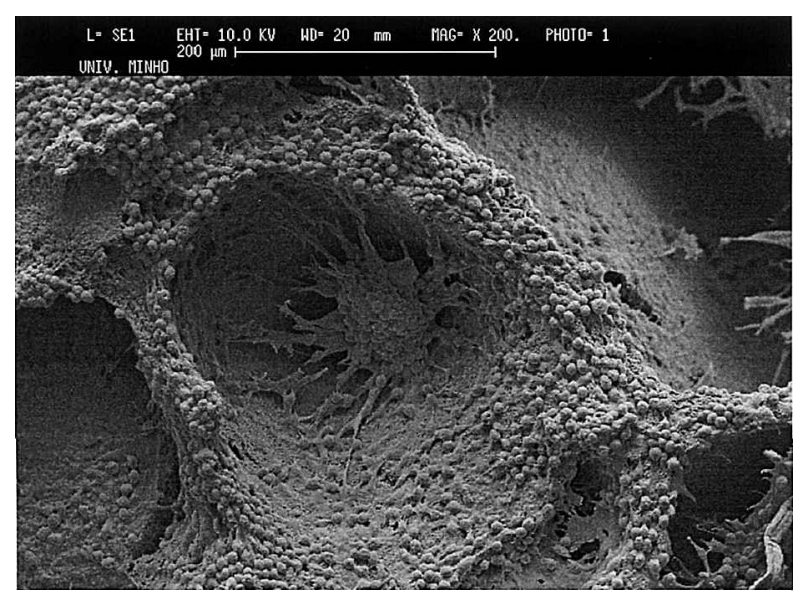

FIG. 4. Continued.

these areas. As expected, this process was less evident when compared with that occurring on the surface of the scaffolds. By week 2 it was possible to observe a higher degree of colonization both on the surface of the material (Fig. 4c) and in the scaffold inner regions (Fig. 4d), accompanied by what seems to be collagen production by the cells (Fig. 4d). Finally, by the end of week 3 (Fig. $4 \mathrm{e}$ and f) and week 4 (Fig. 4g and h), osteoblast-like cells had massively colonized the scaffolds, showing that these were good substrates for cell adhesion and proliferation. These results are not typical for biodegradable polymers because of the continuous change of the surface and release of products due to polymer degradation. In addition, cells were able to enter the scaffold inner regions at every time point (Fig. 4b, d, f, and h). This was an indication that the scaffolds had an adequate porosity for cell migration, and also for three-dimensional cell growth within the porous structures, which are requirements for bone tissue-engineering applications.

Cell proliferation assay (Fig. 5) confirmed the SEM observations, and demonstrated that cells were able to

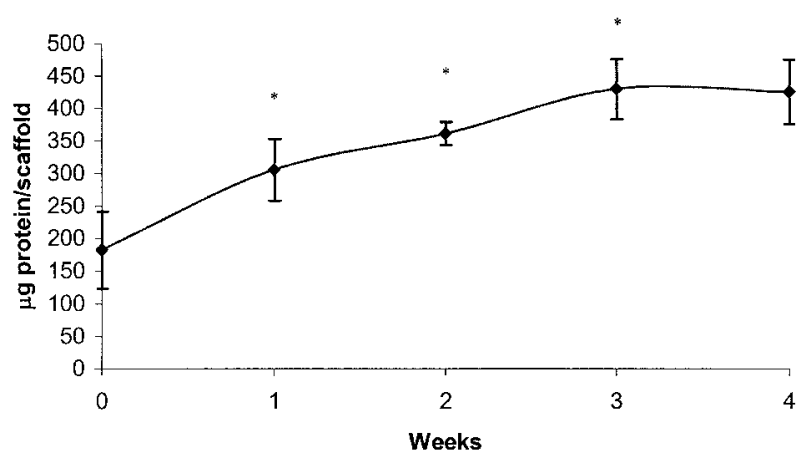

FIG. 5. Cell proliferation was assessed weekly by means of a total protein assay. Cell density used was $3 \times 10^{5}$ cells per scaffold. Cells were kept in culture for 4 weeks in complete culture medium supplemented with $5 \mathrm{mM} \beta$-glycerophosphate, and $50 \mu \mathrm{M}$ ascorbic acid. On the last week of the experiment dexamethasone was added to the culture medium for a final concentration of $10^{-8}$ M. $\left(n=6\right.$; means $\pm \mathrm{SD} ;{ }^{*} p<0.05$. $)$ 


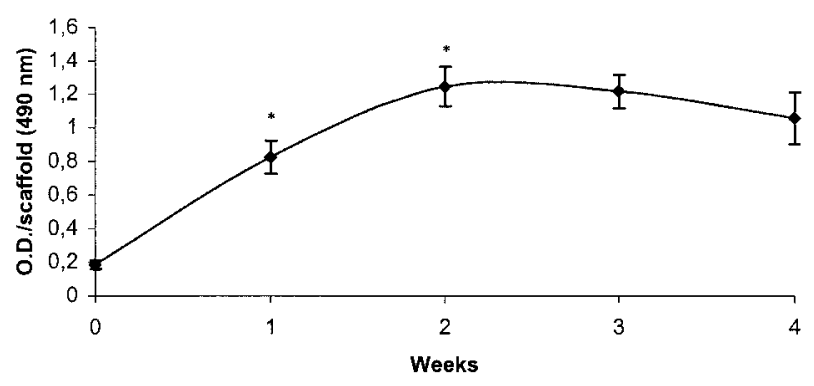

FIG. 6. Cell viability was assessed weekly by the MTS test. Cell density used was $3 \times 10^{5}$ cells per scaffold. Cells were kept in culture for 4 weeks in complete culture medium supplemented with $5 \mathrm{mM} \beta$-glycerophosphate (Sigma), $50 \mu \mathrm{M}$ ascorbic acid (Sigma). On the last week of the experiment dexamethasone was added to the culture medium for a final concentration of $10^{-8}$ M. $\left(n=6\right.$; means $\pm \mathrm{SD} ;{ }^{*} p<0.05$. $)$

grow within the three-dimensional structure. Statistical analysis showed that the growth was always significantly different $(p<0.05)$ in the first 3 weeks of the experiment, being higher during week 1 then in weeks 2 and 3. During week 4 of the experiment cell growth stopped, and a slight decrease in the amount of total protein, which was not significant $(p>0.05)$, was detected. These differences occurred during cell growth into the porous three-dimensional scaffolds and were expected. It is natural that cell growth is higher during the first week, because after a short initial period of adaptation to the new substrate, the cells have an empty substrate available for filling. It is clear that, after this initial period of growth (week 1), during which the cells occupy most of the surface of the three-dimensional porous structure, they will have to find new areas to grow, and so they start to fill the pores and to proliferate into the inner regions of the scaffolds. Because these processes are more complex, the cell growth rate diminishes, which is the reason for the lower growth rate during weeks 2 and 3 of the experiment. After this period of growth, the cells occupy most of the scaffold matrix, and cell growth stops because, once cells reach confluence, cell growth rates are identical to cellular death rates. This is why during week 4 of the experiment there was an arrest in net cell growth. This kind of behavior has already been reported in the literature. ${ }^{8,33}$ Moreover, this fact can also be explained by the addition to the culture medium of dexamethasone, which is a well-known stimulating factor of the osteogenic phenotype and at the same time decreases the rate of cellular growth. ${ }^{34,35}$

Regarding cellular viability, OD values for MTS increased during week $1(p<0.05)$ and week $2(p<0.05)$ of the experiment, being clear that cells were metabolically active (Fig. 6). However, the OD values showed a slight decrease, which was not significant during week 3 $(p>0.05)$ and week $4(p>0.05)$ of the experiment. These decreases in OD values are related to both changes in the metabolism of the cells, probably related to the activation of certain pathways connected with extracellular matrix production, and to the decrease and arrest of cellular growth for the same time periods.

\section{Protein expression}

During the course of bone formation, osteoblasts produce a series of proteins that will make part of the bone ECM, osteopontin being one of them.

In vivo, osteopontin is commonly found in specific regions of bone such as cement lines in remodeling bone and at laminae limitantes at bone surfaces; it is involved in bone remodeling, cell adhesion, extracellular matrix mineralization, and the linking between matrix and mineral, and it is produced by both osteoblasts and osteoclasts. ${ }^{36}$ In vitro, osteopontin is commonly associated with the formation of a collagen-free cement layer on which bone is subsequently deposited ${ }^{36}$

Regarding the present experiment, Western blot analysis clearly revealed that osteopontin was being expressed by cells previously seeded on the scaffolds, during the 4 weeks of the experiment (Fig. 7). This fact, associated with the collagen deposition observed by SEM (Fig. 4d), seems to indicate that active deposition of bone extracellular matrix was happening as well as its probable mineralization.

\section{CONCLUSIONS}

With the present work it was possible to show that scaffolds based on a 50:50 (wt\%) blend of corn starch/ethylene-vinyl alcohol (SEVA-C) present a range of properties that are believed to be adequate for bone tissue-engineering applications. Scaffolds were shown to be noncytotoxic and clearly cytocompatible. Direct contact assays revealed that human osteoblast-like cells were able to grow both on its surface and into the inner parts of the scaffolds. This fact clearly demonstrates that the tested three-dimensional porous structures not only have the right porosity, but also allow for three-dimensional

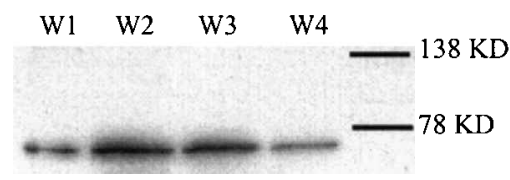

FIG. 7. Western blot analysis of osteopontin expression by SaOS-2 cells seeded on starch-based scaffolds. Protein expression was detected over 4 weeks (W1, W2, W3, and W4), indicating the deposition of bone extracellular matrix (ECM). 
growth of the cells. Finally, protein expression studies associated with SEM observation seem to indicate that bone extracellular matrix was being deposited.

Because of this combination of properties it is strongly believed that the materials and scaffolds herein proposed may be a quite valid alternative to the currently used materials when considering bone regeneration/engineering applications in the near future.

\section{ACKNOWLEDGMENTS}

A.J. Salgado was supported by scholarship SFRH/ $3139 / 2000$ from the Portuguese research council, Fundação para a Ciência e a Tecnologia (FCT). The authors acknowledge Luciano Boesel and Ricardo Carvalho for help with the mechanical testing and characterization of the developed materials. The monoclonal antibody, MPIIIB $10_{1}$, developed by Michael Solursh and Ahnders Franzen, was obtained from the Developmental Studies Hybridoma Bank developed under the auspices of the NICHD and maintained by the University of Iowa, Department of Biological Sciences (Iowa City, IA).

\section{REFERENCES}

1. Temenoff, J.S., and Mikos, A.G. Injectable biodegradable biomaterials for orthopaedic tissue engineering. Biomaterials 21, 2405, 2000.

2. Reis, R.L., and Cunha, A.M. New degradable load-bearing biomaterials composed of reinforced starch based blends. J. Appl. Med. Polym. 4, 1, 2000.

3. Petite, H., Viateau, V., Bensaid, W., Meunier, A., de Pollak, C., Bourguignon, M., Oudina, K., Sedel, L., and Guillemin, G. Tissue engineered bone regeneration. Nat. Biotechnol. 18, 959, 2000.

4. Damien, C., and Parsons, R. Bone graft and bone graft substitutes: A review of current technology and applications. J. Appl. Biomater. 2, 187, 1991.

5. Melican, M.C., Zimmerman, M.C., Dhillon, M.S., Ponnambalam, A.R., Curodeau, A., and Parsons, J.R. Threedimensional printing and porous metallic surfaces: A new orthopedic application. J. Biomed. Mater. Res. 55, 194, 2001.

6. Langer, R., and Vacanti, J.P. Tissue engineering. Science 260, 920, 1993.

7. Yang, S., Leong, K., Du, Z., and Chua, C. The design of scaffolds for use in tissue engineering. I. Traditional factors. Tissue Eng. 7, 679, 2001.

8. Salgado, A.J., Gomes, M.E., Chou, A., Coutinho, O.P., Reis, R.L., and Hutmacher, D.W. Preliminary study on the adhesion and proliferation of human osteoblasts on starch based scaffolds. Mater. Sci. Eng. C 20, 27, 2002.

9. Gomes, M.E., Godinho, J.S., Tchalamov, D., Cunha, A.M., and Reis, R.L. Alternative tissue engineering scaffolds based on starch: Processing methodologies, morphology, degradation and mechanical properties. Mater. Sci. Eng. C 20, 19, 2002.
10. Washburn, N.R., Simon, C.G., Tona, A., Elgendy, H.M., Karim, A., and Amis, E.J. Co-extrusion of biocompatible polymers for scaffolds with co-continuous morphology. J. Biomed. Mater. Res. 60, 20, 2002.

11. Freed, L.E., and Vunjak-Novakovic, G. Culture of organized cell communities. Adv. Drug Deliv. Rev. 33, 15, 1998.

12. Hutmacher, D.W. Polymeric scaffolds in tissue engineering of bone and cartilage. Biomaterials 21, 2529, 2000.

13. Vacanti, C.A., Bonassar, L.J., Vacanti, M.P., and Shufflebarger, J. Replacement of an avulsed phalanx with tissueengineered bone. N. Engl. J. Med. 344, 1511, 2001.

14. Ohgushi, H., Dohi, Y., Tamai, S., and Tabata, S. Osteogenic differentiation of marrow stromal stem cells in porous hydroxyapatiteceramics. J. Biomed. Mater. Res. 27, 1401, 1993.

15. Ohgushi, H., and Caplan, A.I. Stem cell technology and bioceramics: From cell to gene engineering. J. Biomed. Mater. Res. 48, 913, 1999.

16. Noshi, T., Yoshikawa, T., Ikeuchi, M., Dohi, Y., Ohgushi, H., Horiuchi, K., Sugimura, M., Ichijima, K., and Yonemasu, K. Enhancement of the in vivo osteogenic potential of marrow/hydroxyapatite composites by bovine bone morphogenetic protein. J. Biomed. Mater. Res. 52, 621, 2000.

17. Thomson, R.C., Mikos, A.G., Beahm, E., Lemon, J.C., Satterfield, W.C., Aufdemorte, T.B., and Miller, M.J. Guided tissue fabrication from periosteum using preformed biodegradable polymer scaffolds. Biomaterials 20, 2007, 1999.

18. Whang, K., Healy, K.E., Elenz, D.R., Nam, E.K., Tsai, D.C., Thomas, C.H., Nuber, G.W., Glorieux, F.H., Travers, R., and Sprague, S.M. Engineering bone regeneration with bioabsorbable scaffolds with novel microarchitecture. Tissue Eng. 5, 35, 1999.

19. Perka, C., Schultz, O., Spitzer, R.S., Lindenhayn, K., Burmester, G.R., and Sittinger, M. Segmental bone repair by tissue-engineered periosteal cell transplants with bioresorbable fleece and fibrin scaffolds in rabbits. Biomaterials 21, 1145, 2000.

20. Reis, R.L., and Cunha, A.M. Starch and starch based blends. In: Buschow, K.H.J., Cahn, R.W., Flemings, M.C., Ilschner, B., Kramer, E.J., and Mahajan, S., eds. Biological and Biomimetic Materials. Amsterdam: PergamonElsevier Science, 2001, pp. 8810-8816.

21. Malafaya, P.B., Elvira, C., Gallardo, A., San Román, J., and Reis, R.L. Processing and characterization of new porous biodegradable starch-based delivery system for arthritis and rheumatism treatment. J. Biomater. Sci. Polym. Ed. 12, 1227, 2001.

22. Pereira, C.S., Cunha, A.M., Reis, R.L., Vázquez, B., and San Roman, J. New starch-based thermoplastic hydrogels for use as bone cements or drug delivery carriers. J. Mater. Sci. Mater. Med. 9, 825, 1998.

23. Reis, R.L., Cunha, A.M., and Bevis, M.J. Using nonconventional processing routes to develop anisotropic and biodegradable composites of starch based thermoplastics reinforced with bone-like ceramics. J. Appl. Med. Polym. 2, 49, 1998.

24. Gomes, M.E., Ribeiro, A.S., Malafaya, P.B., Reis, R.L., and Cunha, A.M. A new approach based on injection moudling to produce biodegradable starch based polymeric 
scaffolds: Morphology, mechanical and degradation behavior. Biomaterials 22, 883, 2001.

25. Mendes, S.C., Reis, R.L., Bovell, Y.P., Cunha, A.M., van Blitterswijk, C.A., and de Bruijn, J.D. Biocompatibility testing of novel starch-based materials with potential application in orthopaedic surgery: A preliminary study. Biomaterials 22, 2057, 2001.

26. ISO document 10993. Biological compatibility of medical devices. 5. Test for cytotoxicity: In vitro methods. December 1992.

27. Cory, A.H., Owen, T.C., Barltrop, J.A., and Cory, J.G. Use of an aqueous soluble tetrazolium/formazan assay for cell growth assays in culture. Cancer Commun. 3, 207, 1991.

28. Salih, V., Franks, K., James, M., Hastings, G.W., and Knowles, J.C. Development of soluble glasses for biomedical use. II. The biological response of human osteoblast cell lines to phosphate-based soluble glasses. J. Mater. Sci. Mater. Med. 11, 615, 2000.

29. Maquet, V., and Jerome, R. Design of biodegradable polymer scaffolds for cell transplantation. Mater. Sci. Forum 250, 15, 1997.

30. Temenoff, J.S., Lu, L., and Mikos, A.G. Bone tissue engineering using synthetic biodegradable polymer scaffolds. In: Davies, J.E., ed. Bone Engineering. Toronto: $\mathrm{em}^{2}$, 1999, pp. $454-461$.

31. Steele, J.G., Dalton, B.A., Thomas, C.H., Healy, K.E., Gengenbach, T.R., and McFarland, C.D. Underlying mechanisms of cellular adhesion in vitro during coloniza- tion of synthetic surfaces by bone-derived cells. In: Davies, J.E., ed. Bone engineering.Toronto: em², 1999, pp. 225-231.

32. Horbett, T.A., Cooper, K.W., Lew, K.R., and Ratner, B.D. Rapid postadsorpativechanges in fibrinogen adsorbed from plasma to segmented polyurethanes.J. Biomater. Sci. Polym. Ed. 9, 1071, 1998.

33. Shea, L.D., Wang, D., Francheshi, R.T., and Mooney, D.J. Engineered bone development from a pre-osteoblast cell line on three-dimensional scaffolds. Tissue Eng. 6, 605, 2000.

34. Hulley, P.A., Gordon, F., and Hough, F.S. Inhibition of mitogen-activated protein kinase activity. Endocrinology 139, 2423, 1998.

35. Ogston, N., Harrison, A.J., Cheung, H.F.J., Ashton, B.A., and Hampson, G. Dexamethasone and retinoic acid differentially regulate growth and differentiation in an immortalised human clonal bone marrow stromal cell line with osteoblastic characteristics. Steroids 67, 895, 2002.

36. Sodek, J., Ganss, B., and McKee, M.D. Osteopontin. Crit. Rev. Oral Biol. Med. 11, 279, 2000.

Address reprint requests to: António José Salgado 3B's Research GroupBiomaterials, Biodegradables, Biomimetics University of Minho

Campus de Gualtar 4710-057 Braga, Portugal

E-mail: asalgado@dep.uminho.pt 